\title{
Wolff-Parkinson-White syndrome presenting as atrial fibrillation in a female patient with situs inversus
}

\author{
Ben Ghezala Hassen, Snouda Salah, Abbes Fehmi, Bechikh Imen
}

\begin{abstract}
Introduction: Wolff-Parkinson-White (WPW) syndrome is a conduction disturbance characterized by the presence of an accessory pathway between the atria and the ventricles. Among patients with WPW syndrome, atrioventricular reentrant tachycardia (AVRT) is the most common arrhythmia. Atrial fibrillation associated with WPW is less common but potentially life-threatening arrhythmia as it can degenerate to ventricular fibrillation (VF). Case Report: We report a case of wide-QRS tachycardia with which was subsequently diagnosed as WPW syndrome with atrial fibrillation (AF) in a patient with dextrocardia situs inversus. Treated initially by electrical conversion and then in a second plane by catheter ablation. Conclusion: WPW syndrome is not infrequently encountered in the patient presenting to the emergency department with tachyarrhythmias. Once symptomatic, patients can be treated with or can try medications to control their symptoms. A particular attention must be paid to patients with dextrocardia situs inversus, especially in ECG record and electrical cardioversion.
\end{abstract}

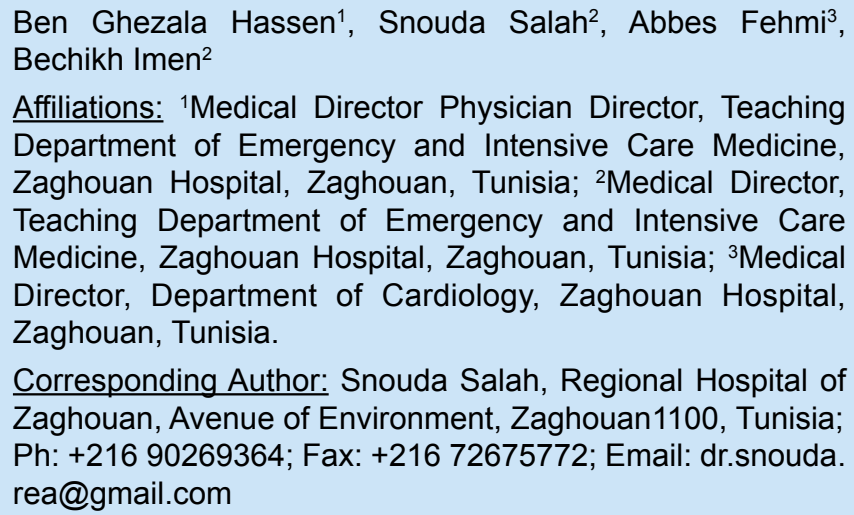

Received: 15 February 2015

Accepted: 15 May 2015

Published: 01 June 2015
Keywords: Atrial fibrillation, Dextrocardia, Situs inversus, Wolff-Parkinson-White (WPW) syndrome

\section{How to cite this article}

Hassen BG, Salah S, Fehmi A, Imen B. WolffParkinson-White syndrome presenting as atrial fibrillation in a female patient with situs inversus. Case Rep Int 2015;4:14-17.

Article ID: 100009CRINTBH2015

$$
* * * * * * * * *
$$

doi:10.5348/crint-2015-9-CR-4

\section{INTRODUCTION}

Wolff-Parkinson-White (WPW) syndrome is a conduction disturbance characterized by the presence of an accessory pathway between the atria and the ventricles (Kent bundle), which provides an alternative route for ventricular activation [1]. WPW syndrome may occur in patients with a normal heart, but also it can be associated with congenital heart disease (Ebstein's anomaly, atrial and ventricular septal defects, coronarysinus diverticula) [2]. It is defined by a shortened PR interval ( $<0.12$ second) with normal $\mathrm{P}$ wave, wide QRS complex and the presence of a delta wave [3]. The most common arrhythmia associated with this syndrome is the atrioventricular reentrant tachycardia (AVRT). Atrial fibrillation associated with WPW is less common but potentially life-threatening arrhythmia as it can degenerate to ventricular fibrillation (VF). We report a case of wide-QRS tachycardia which was subsequently diagnosed as WPW syndrome with atrial fibrillation (AF) in a patient with situs inversus. 


\section{CASE REPORT}

This case is about a 33-year-old, non-hypertensive and non-diabetic female, who was presented to emergency complaining of palpitations without chest pain, dyspnea, or syncope. She had a history of situs inversus with dextrocardia, without associated malformations (Figure 1). On physical examination, pulse rate was $150 / \mathrm{min}$, irregular. Her blood pressure was $80 / 60 \mathrm{mmHg}$. No other abnormality was detected on physical examination. The electrocardiogram revealed Irregularly irregular, wide-QRS complex tachycardia with broad complexes at a rate of $300 /$ minute (Figure 2). The diagnosis of atrial fibrillation was made. The patient was managed with electrical cardioversion of 200 Joules because of hemodynamic instability. Sinus rhythm was achieved, and the review of the electrocardiogram revealed a short $\mathrm{P}-\mathrm{R}$ interval and the presence of the delta wave, suggestive of WPW type of pre-excitation syndrome (Figure 3). Transthoracic echocardiography revealed normal echocardiographic findings with normal left ventricular systolic function. She was referred for electrophysiological studies. The accessory pathway was identified and found to be capable of fast antegrade conduction. She was successfully treated with radiofrequency ablation (Figure 4).

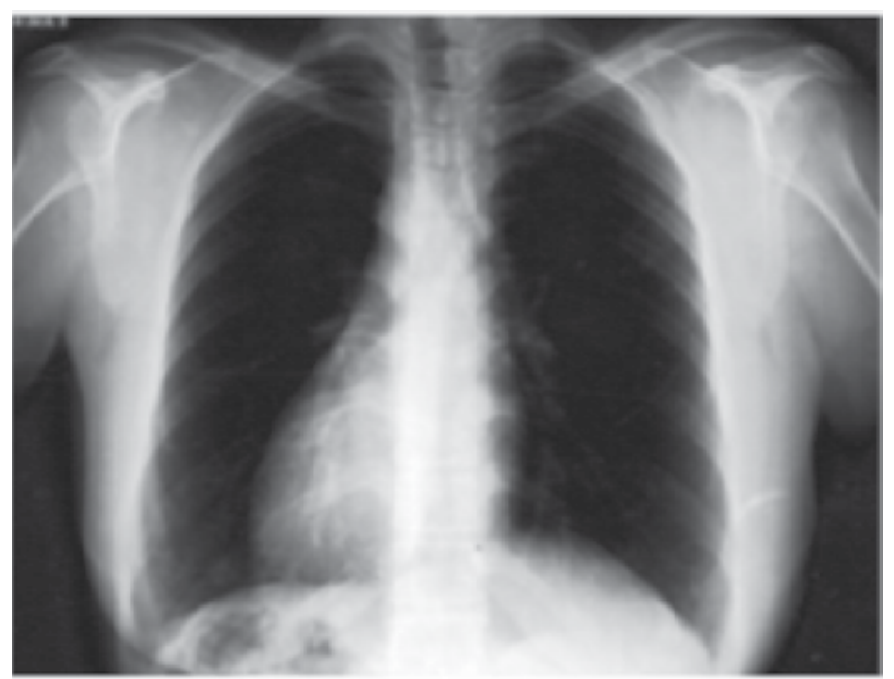

Figure 1: Chest X-ray showing dextrocardia.

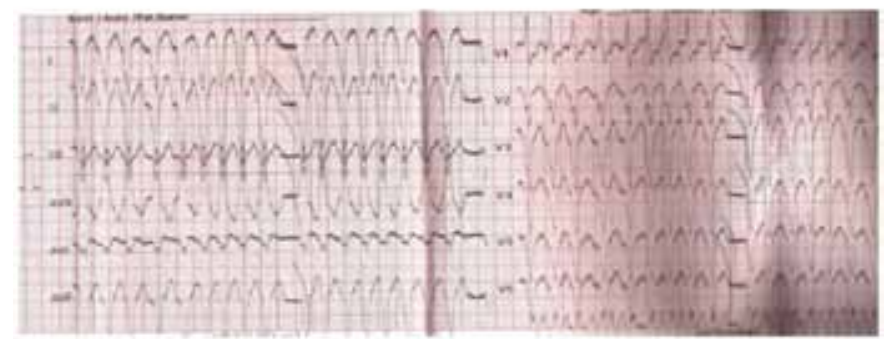

Figure 2: Twelve lead ECG of patient showing irregular, wideQRS complex tachycardia.

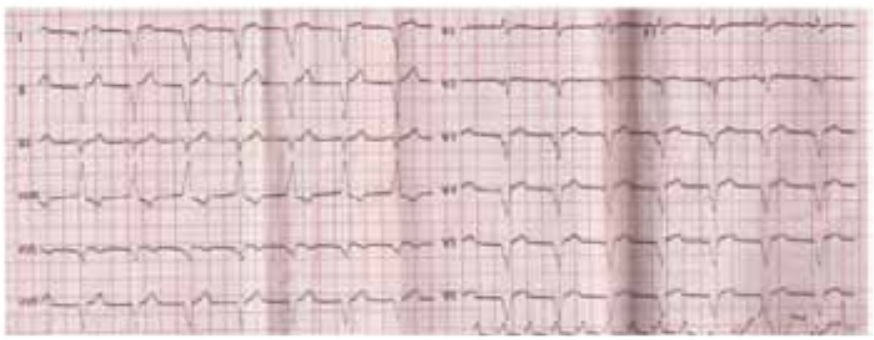

Figure 3: Twelve lead ECG of patient showing WPW type of preexcitation after electrical cardioversion.

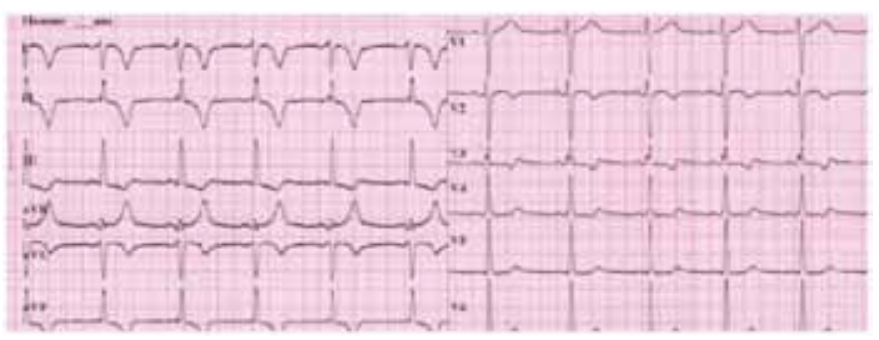

Figure 4: Twelve lead ECG of patient after radiofrequency ablation.

\section{DISCUSSION}

In the normal electrocardiogram, $\mathrm{P}$ wave represent the electrical activity generated from the sino-atrial node. The electrical impulse then moves to an area known as the atrio-ventricular node (AVN) where is held up for a brief period. This delay is recorded as a PR interval. It represents the time frame from the beginning of atrial depolarization to the beginning of ventricular depolarization. This interval is needed to allow the mechanical emptying of atrial blood into the ventricles. Patients with WPW have a tract that bypasses the AVN known as the Kent bundle. The impulse travels down both the AVN and the Kent bundle, causing early depolarization of the ventricular myocardium and a shortened PR interval on the ECG. The AVN impulse is much faster than transmission of the Kent bundle impulse through the myocardium, and the fusion of the two waves forms a fusion beat with a delta wave on the ECG. The existence of an accessory pathway without the physiological delay of the cardiac impulse in the AVN causes arrhythmias. The most frequent arrhythmia associated with WPW syndrome are paroxysmal supraventricular tachycardia caused by atrioventricular re-entry, and auricular fibrillation (AF) with a rapid ventricular response [4]. Certainly, the ECG is very important in the diagnosis of WPW syndrome and in the localization of the accessory pathway, but it can be mistaken for myocardial infarction, Bundle branch block and ventricular hypertrophy. The appropriate management is based on the risk stratification and the identification of associated conditions [5]. Although the ECG morphology varies widely, especially in the presence of anatomic aberration like situs inversus with dextrocardia, which make the ECG interpretation very difficult. The classic electrocardiographic presentation of dextrocardia consists of [6]: 
- Global negativity in lead I.

- Positively deflected QRS complex in aVR.

- Negative P-wave in lead II.

- Reverse R-wave progression in precordial leads.

- Right axis deviation.

To record ECG in situs inversus patient we should reverse the arm leads, reverse V1 and V2 and place the other chest electrodes symmetrically on the right chest in usual intercostal spaces. WPW syndrome is the association of WPW pattern (shortened PR interval and delta wave on the ECG) and episodes of tachycardia. The major risk of WPW syndrome is the frequent development of supraventricular tachycardias whose incidence is reported to be $40-80 \%$. The AVRT is the most common tachycardia in WPW syndrome $(75-80 \%)$. AF is less common (20-25\%) [7].

Treatment of WPW depends on the clinical presentation. For asymptomatic patients with only a documented WPW pattern on their ECG without documented tachycardia, simple conservative observation may be appropriate. Vagal manoeuvres may be used in stable symptomatic patients to block the AVN conduction. But, the mainstay of the treatment of AVRTs consists of interrupting the re-entrant circuit. Calcium channel blockers, beta-blockers and digitalis do not act on the bypass tract, and the transmission through the accessory pathway would increase, with a corresponding increase in ventricular rate. This could have disastrous consequences, possibly causing the arrhythmia to deteriorate into ventricular fibrillation. Hence, it is important to use drugs like class Ic anti-arrhythmics and amiodarone, which act on bypass tract as well as AVN, to terminate AF [8]. A hemodynamically compromised patient with an AVRT or AF must undergo electrical cardioversion. In our case, the electric cardioversion was indicated but because of the dextrocardia situs inversus we had to change the placement of defibrillator pads. In this case, traditional pad placement can be mirrored, or we can use the anterior/posterior placement to the right of the patient's sternum [9]. Significant advances have been made in the field of electrophysiological studies. Radiofrequency catheter ablation has become the treatment of choice for patients with symptomatic tachyarrhythmias with initial efficacy of $95 \%$ [10] with a mortality rate between $0 \%$ and $0.2 \%$ [11].

\section{CONCLUSION}

Wolff-Parkinson-White (WPW) syndrome is the association of WPW pattern and episodes of tachycardia. It is not infrequently encountered in the patient presenting to the emergency department with tachyarrhythmias. We can try medications for symptomatic patients, but the catheter ablation remains the mainstay of the treatment. A particular attention must be paid to patients with dextrocardia situs inversus, especially in ECG record and electrical cardioversion. Recent advances in diagnostic and therapeutic procedures in this field mean that the long-term prognosis for these patients is good.

$$
* * * * * * * * *
$$

\section{Author Contributions}

Ben Ghezala Hassen - Conception and design, Acquisition of data, Analysis and interpretation of data, Drafting the article, Critical revision of the article, Final approval of the version to be published

Snouda Salah - Conception and design, Acquisition of data, Analysis and interpretation of data, Drafting the article, Critical revision of the article, Final approval of the version to be published

Abbes Fehmi - Conception and design, Acquisition of data, Analysis and interpretation of data, Drafting the article, Critical revision of the article, Final approval of the version to be published

Bechikh Imen - Conception and design, Acquisition of data, Analysis and interpretation of data, Drafting the article, Critical revision of the article, Final approval of the version to be published

\section{Guarantor}

The corresponding author is the guarantor of submission.

\section{Conflict of Interest}

Authors declare no conflict of interest.

\section{Copyright}

(C) 2015 Ben Ghezala Hassen et al. This article is distributed under the terms of Creative Commons Attribution License which permits unrestricted use, distribution and reproduction in any medium provided the original author(s) and original publisher are properly credited. Please see the copyright policy on the journal website for more information.

\section{REFERENCES}

1. Wood FC, Wolferth CC, Geckeler GD. Histologic demonstration of accessory muscular connections between auricle and ventricle in a case of short PR interval and prolonged QRS complex. Am Heart J 1943;25:454-62.

2. Deal BJ, Keane JF, Gillette PC, Garson A Jr. WolffParkinson-White syndrome and supraventricular tachycardia during infancy: management and followup. J Am Coll Cardiol 1985 Jan;5(1):130-5.

3. Gallagher JJ, Pritchett EL, Sealy WC, Kasell J, Wallace AG. The preexcitation syndromes. Prog Cardiovasc Dis 1978 Jan-Feb;20(4):285-327.

4. Wellens HJ, Brugada P, Penn OC. The management of preexcitation syndromes. JAMA 1987 May 1;257(17):2325-33.

5. Jones MB, Glancy DL, Jain N. The Wolff-ParkinsonWhite electrocardiogram. A follow-up study of five to twenty-eight years. N Engl J Med 1968 Feb 29;278(9):492-4. 
6. Jones MB, Glancy DL, Jain N. ECG of the month: rightaxis deviation of the QRS complex with precordial $\mathrm{R}$-wave regression. Situs inversus with mirror-image dextrocardia, sinus rhythm, and a long P-R interval. J La State Med Soc 2009 May-Jun;161(3):125-8.

7. Chung EK. Wolff-Parkinson-White syndrome. In: Principles of Cardiac Arrhythmias, 2nd ed. Baltimore: The Williams \& Wilkins Company 1977;415-35.

8. Olgin JE, Zipes DP. Specific arrhythmias: Diagnosis and Treatment. In: Eugene Braunwald et al ed. Heart Disease, 6th ed: Philadelphia: W.B. Saunders company 2001;815-89.

9. Gorenek B, Kuskus S, Kudaiberdieva G, et al. Electrical cardioversion of atrial fibrillation in a case of dextrocardia. Can J Cardiol 2004 Jun;20(8):81921.

10. Morady F. Catheter ablation of supraventricular arrhythmias: state of the art. Pacing Clin Electrophysiol 2004 Jan;27(1):125-42.

11. Pappone C, Santinelli V, Rosanio S, et al. Usefulness of invasive electrophysiologic testing to stratify the risk of arrhythmic events in asymptomatic patients with Wolff-Parkinson-White pattern: results from a large prospective long-term follow-up study. J Am Coll Cardiol 2003 Jan 15;41(2):239-44.
Access full text article on other devices

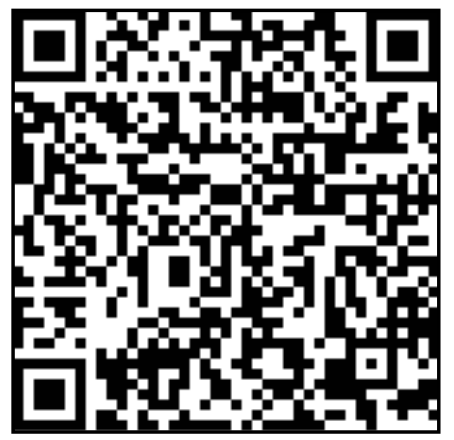

Access PDF of article on other devices

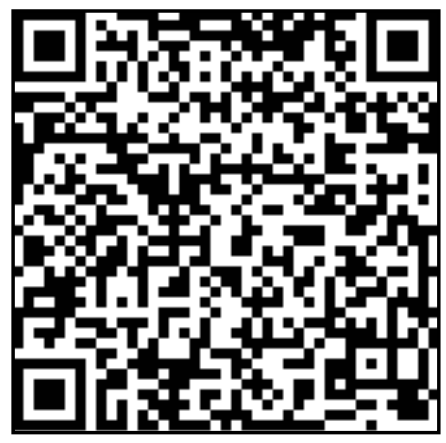

